\title{
PEMBERDAYAAN IBU RUMAH TANGGA DI KELURAHAN 12 ULU DALAM UPAYA MENJAGA KEBERSIHAN LINGKUNGAN DENGAN KETERAMPILAN SENI DAUR ULANG LIMBAH PLASTIK
}

\author{
Ervina Mukharomah ${ }^{1 *}$, Etty Nurmala Fadhillah ${ }^{1}$, Binar Azwar Anas Harfian ${ }^{1}$ \\ ${ }^{1}$ Program Studi Pendidikan Biologi, Universitas Muhammadiyah Palembang, Palembang, Indonesia \\ *Penulis Korespodensi: mukharomah.ervina@gmail.com
}

\begin{abstract}
Abstrak
Kegiatan Pengabdian Kepada Masyarakat ini dilakukan dengan tujuan sebagai upaya dalam menyelamatkan lingkungan dari bahaya limbah plastik. Model kegiatan yang dilakukan dalam kegiatan pengabdian adalah bentuk Pelatihan keterampilan seni daur ulang limbah kepada ibu-ibu rumah tangga dalam mengolah limbah plastik di lorong pedatukkan darat Kelurahan 12Ulu Kota Palembang. Adapun manfaat dari kegiatan pengabdian kepada masyarakat ini diharapkan masyarakat di lingkungan kelurahan 12 ulu lorong Pedatukkan Darat terbebas dari sampah plastik sehingga tidak terlihat lagi sampah-sampah plastik yang mencolok dari kejauhan. Kegiatan pengabdian secara keseluruhan dapat dikatakan baik dan berhasil, dilihat dari keberhasilan target jumlah peserta pelatihan (100\%), ketercapaian tujuan pelatihan $(85 \%)$, dan kemampuan peserta dan penguasaan materi (80\%). Kegiatan pengabdian dapat meningkatkan pengetahuan ibu-ibu rumah tangga tentang pengelolaan sampah anorganik terutama plastik menjadi aneka kreasi tas daur ulang, serta memberdayakan mereka dalam pengelolaan sampah anorganik berupa plastik menjadi aneka kreasi tas daur ulang.
\end{abstract}

Kata kunci: Pemberdayaan, limbah plastik, daur ulang, lingkungan, kelurahan 12 Ulu.

\begin{abstract}
The Community Service activities are carried out with the aim of efforts to save the environment from the dangers of plastic waste. The model of the activities carried out in the service activities is a form of training in the recycling of art skills to housewives in processing plastic waste in the terrain of land terrain in the 12Ulu sub-district of Palembang City. As for the benefits of community service activities, it is expected that the community in the neighborhood of 12 ulu Pedatukan Darara corridors will be free from plastic waste, so that no visible plastic waste can be seen from a distance. Overall service activities can be said to be good and successful, seen from the success of the target number of trainees (100\%), achievement of training objectives (85\%), and participants' ability and mastery of the material (80\%). Service activities can increase the knowledge of housewives about the management of inorganic waste, especially plastic, into various recycled bag creations, and empower them in managing inorganic waste in the form of plastic into various recycled bag creations.
\end{abstract}

Keywords: Empowerment, plastic waste, recycling, environment, 12 Ulu village.

\section{PENDAHULUAN}

Kemajuan teknologi di era globalisasi ini membuat semua serba instan. Bukan hanya dari tingkat komunikasi yang terlihat instan tetapi semua aspek menjadi lebih instan. Salah satu yang menjadi problema akibat kemajuan teknologi ialah banyak sekali bahanbahan kebutuhan rumah tangga yang instan. Mulai dari mie instan, minuman botol, kopi instan dll. Akibat dari hal itu semakin banyak limbah plastik yang dihasilkan. Setelah sekian banyak sampah dihasilkan muncullah cara-cara dan solusi untuk mengelola limbah. Mulai dari 3R (Reduse, reuse, Recycle) adapula penanggulangan sampah dengan pengomposan. Dalam hal ini masyarakatlah yang ikut andil.
Pada dasarnya masyarakat memiliki peran penting dalam mewujudkan lingkungan yang bersih, rapi, indah,dan sehat. Tetapi terkadang karena pengetahuannya yang kurang sehingga masyaraka kurang paham bagaimana cara menjaga lingkungan sekitarnya agar terjaga kebersihannya. Oleh sebab itu masyarakat perlu diberikan sosialisasi dan wawasan agar mengerti bagaimana cara menjaga lingkungannya, bagaimana cara menyikapi sampah dan limbah rumah tangga. Sosialisasi yang diberikan kepada masyarakat merupakan bentuk pendidikan dan pengetahuan mengenai lingkungan hidup masyarakat dalam upaya dapat memanfaatkan sampah menjadi sesuatu yang memiliki nilai ekonomi. Menurut UU No 32 (2009) bahwa lingkungan hidup adalah kesatuan ruang dengan semua benda, keadaan, dan makhluk hidup, termasuk 
manusia dan perilakunya yang mempengaruhi alam itu sendiri serta kelangsungan perikehidupan dan kesejahteraan manusia serta makhluk hidup lain.

Limbah adalah sisa suatu usaha kegiatan dalam kehidupan manusia atauaktivitas alam yang mengganggu. Contoh usaha pembuatan tahu menimbulkanlimbah berupa air asam, ampas kedelai, abu hasil pembakaran, dan lain-lain.Dalam konsentrasi dan kuantitas tertentu kehadiran limbah dapat berguna, namunjika berlebihan akan sangat merugikan dan merusak lingkungan terutama bagi kesehatan manusia. Tingkat keracunan yang ditimbulkan limbah tergantung pada jenis dan karakteristik limbah (Arief, 2012).

Menurut Hadi (2015), Suatu limbah belum tentu dikategorikan sebagai penyebab pencemaran lingkungan apabila kita dapat melakukan limbah itu dengan baik dan sesuai dengan dasar keilmuan. Akan tetapi, suatu limbah pun dapat menyebabkan pencemaran lingkungan ketika jumlah kandungan zatzatnya sudah melebihi ambang batas kemampuan lingkungan untuk mendaur ulangnya. Keadaan tersebut terjadi karena kelalaian dan ketidak pedulian kita terhadap kondisi lingkungan.Limbah memiliki kualitas tertentu mengenai dampak yang dapat ditimbulkannya.Kualitas limbah tersebut dipengaruhi oleh beberapa faktor berikut.
a. Volume limbah
b. Kandungan bahan pencemar
c. Frekuensi pembuangan limbah

Adapun tingkat bahaya keracunan yang ditimbulkan oleh limbah bergantung padajenis dan karakteristik limbah, antara lain:
a. Berukuran mikro.
b. Dinamis.
c. Berdampak luas (penyebarannya).
d. Berdampak jangka panjang (antargenerasi).

Limbah berdasarkan jenis senyawanya dibedakan menjadi limbah organik dan limbah anorganik. Limbah organik adalah limbah yang mengandung unsur hidrokarbon, yaitu unsur hidrogen dan unsur karbon. Contohnya kotoran hewan danmanusia, sisa makanan, sisa tumbuhan mati, dan lain-lain. Namun secara teknissebagian orang mendefinisikan limbah organik sebagai limbah yang berasaldari makhluk hidup (alami) dan sifatnya mudah membusuk. Artinya, bahanbahanorganik alami sulit membusuk/terurai, seperti kertas dan bahan organik sintetis sulit membusuk, seperti plastik dan karet tidak termasuk dalam limbah organik. Limbah anorganik adalah limbah yang selain mengandung zat-zat kimia anorganik, juga mengandung zat-zat kimia organik yang sulit diuraikan oleh mikroorganisme (Ginting, 2017). Contoh limbah anorganik, yaitu besi bekas, pecahan kaca, plastik, kaleng bekas, kertas dan sisa pemupukan (mengandung unsur nitrogen, fosfor, dan unsur sintetis lainnya). Limbah anorganik tidak dapat dibiarkan begitu saja karena sulit diuraikan secara alami oleh organisme, tetapi harus ada usaha untuk mendaur ulangnya.
Plastik merupakan salah satu jenis makromolekul yang dibentuk dengan proses polimerisasi. Dimana polimerisasi merupakan suatu proses penggabungan beberapa molekul sederhana melalui proses kimia menjadi molekul besar. Plastik merupakan senyawa polimer yang unsur penyusun utamanya adalah Karbon dan Hidrogen. Untuk membuat plastik, salah satu bahan baku yang sering digunakan adalah Naphta, yaitu bahan yang dihasilkan dari penyulingan minyak bumi atau gas alam. Sebagai gambaran, untuk membuat $1 \mathrm{~kg}$ plastik memerlukan $1,75 \mathrm{~kg}$ minyak bumi, untuk memenuhi kebutuhan bahan bakunya maupun kebutuhan energi prosesnya (Kumar dkk., 2011).

Menurut Ricky (2015), berdasarkan wujudnya, limbah dibedakan menjadi limbah cair, limbah padat, limbah gas, dan limbah suara. Limbah cair adalah segala jenis limbah yang berwujud cair, berupa air beserta bahanbahan buangan lain yang tercampur (tersuspensi) maupunterlarut dalam air.

Limbah padat merupakan salah satu limbah yang paling banyak terdapat lingkungan. Biasanya limbah padat disebut sebagai sampah. Bentuk,jenis, dan komposisi limbah padat sangat dipengaruhi oleh taraf hidupmasyarakat dan kondisi alam, sedangkan jumlahnya sangat dipengaruhi oleh kepadatan penduduk. Umumnya, semakin padat populasi di suatu daerah, akan semakin besar pula produksi limbah padatnya (Nusa, 2010).

Limbah gas merupakan limbah yang keberadaannya ada di udara sekitar atau di lapisan atmosfer bumi kita. Saat ini, penyumbang limbah gas paling besar dihasilkan dari pembakaran bahan bakar minyak bumi, seperti bensin, solar, minyak tanah, dan lain-lain. Limbah gas yang paling banyak dihasilkan dari proses kehidupan adalah gas karbon dioksida $\left(\mathrm{CO}_{2}\right)$. Gas karbon dioksida ini merupakan salah satu penyebab terbesar atas terjadinya pemanasan global atau global warming. Pada umumnya, jenis limbah gas yang ada di udara terdiri dari berbagai macam senyawa kimia (Silviana, 2010).

Limbah suara adalah limbah yang berupa gelombang bunyi yang merambat di udara. Limbah suara dapat dihasilkan dari mesin kendaraan, mesin-mesin pabrik, peralatan elektronik (seperti televisi dan radio), dan sumber-sumber lainnya. Kadar limbah suara yang dapat ditoleransi untuk kitaadalah $80 \mathrm{~dB}$.

Definisi Bahan Berbahaya dan Beracun (B3) menurut PP RI No. 18/1999 tentang Pengolahan Limbah Bahan Berbahaya dan Beracun adalah sisa suatukegiatan yang mengandung bahan berbahaya dan beracun, yang karena sifatdan/atau konsentrasinya, baik secara langsung maupun tak langsung merusaklingkungan hidup, kesehatan, maupun manusia. Sehingga masyarakat sangat berperan pentinng.

Masyarakat yang akan menjadi mitra PKM ini merupakan rata-rata masyarakat golongan menengah ke 
bawah dengan tingkat pendidikan paling banyak SMP, pekerjaan sebagai ibu rumah tangga dan beberapa bekerja di pasar 16 ilir sebagai buruh pengupas bawang. Lokasi Mitra PKM di kelurahan 12 ulu banyak terlihat sampah-sampah berserakan. Terlebih lagi sampah plasik yang berwarna warni terlihat mencolok dari kejauhan. Dari hasil observasi ternyata masyarakat setempat lebih sering membeli shampo, detergen, kopi sachet dikarenakan faktor ekonomi yang pas-pasana. Hal tersebut yang membuat sampah plastik semakin mendominasi tumpukan sampah yang ada. Padahal sampah plastik apabila tidak ditangani dengan baik akan berdampak buruk pada lingkungan sekitar.

Dampak yang akan terjadi apabila sampah plastik hanya dibuang ke lingkungan yaitu salah satunya membuat saluran air tersumbat sehingga mengakibatkan banjir. Oleh sebab itu perlu dicarikan solusi sebagai cara menyikapi sampah anorganik berupa plastik yang sulit terurai ini secara bijak agar dapat dimanfaatkan potensinya. Pada dasarnya sampah-sampah plastik yang hanya dibuang ke lingkungan sebenarnya memiliki nilai ekonomi apabila diolah. Pengolahan sampah plastik dengan menerapkan keterampilan seni akan membuahkan suatu karya indah yang memiliki nilai ekonomi . Salah satu contoh yang dapat dibuat dari bahan dasar plastik bekas ialah kotak pensil, tas, keranjang belanja dll.

Sehingga dilakukan pengabdian masyarakat ini dengan tujuan agar masyarakat sekitar 12 ulu Kota Palembang tidak membuang sampah plastik sembarangan. Tetapi sampah plastik tidak dibuang ke lingkungan dan di olah menjadi kerajinan. Hal ini dapat bermanfaat bagi lingkungan yang terlihat bersih dan menjadi peluang usaha.

\section{METODE KEGIATAN}

Khalayak dan sasaran dalam kegiatan pengabdian kepada masyarakat ini adalah ibu RT dan warga masyarakat lorong Pedatukkan darat Kelurahan 12Ulu Palembang. Masyarakat yang terlibat sebanyak 40 orang yang terdiri dari Ibu RT, Ibu-Ibu rumah tangga, remaja, dan 2 mahasiswa pendidikan Biologi FKIP UMP.

Kegiatan Pemberdayaan masyarakatn terhadap seni daur ulang limbah plastik ini dilaksanakan di Rumah Warga Lorong Pedatukkan Darat Kelurahan 12Ulu Palembang, pada tanggal 1 September 2018 mulai dari pukul 10.00-15.00 WIB. Model kegiatan yang dilakukan dalam kegiatan pengabdian adalah bentuk Pelatihan keterampilan seni dalam mengolah limbah plastik di lorong pedatukkan darat Kelurahan 12 Ulu Kota Palembang. Susunan kegiatan pelatihan ini terdiri atas:

a. Absensi dan Pembukaan

b. Penyampaian materi dengan metode pelatihan melalui pendampingan, dan dibantu menggunakan slide dan video

c. Pembagian Print Out materi d. Praktek pengolahan limbah plastik menjadi barang bernilai ekonomi

e. Penutup

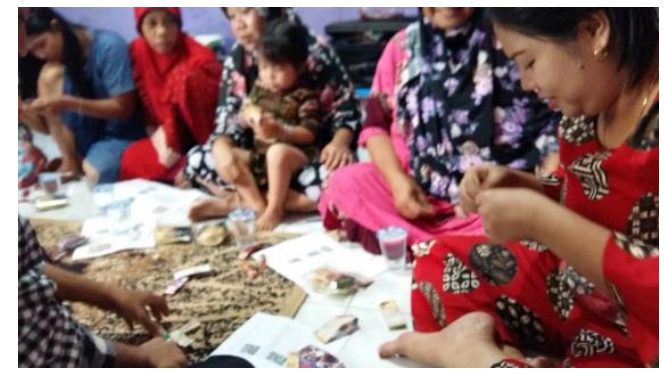

Gambar 1. Kegiatan Ibu-ibu.

Kegiatan pengabdian ini dihadiri oleh Ibu RT dan ibuibu rumah tangga. Menurut ibu RT daerah tersebut masih banyak msyarakatnya yang membeli barang kebutuhan sehari-hari dalam bentuk sachet. Misalnya kopi, shampo, detergen, susu dan sebagainya. Sehingga nampak sampah plastik bertaburan di sekitar jalan.

\section{HASIL DAN PEMBAHASAN}

Pelatihan yang dilaksanakan di rumah warga pada tanggal 1 September 2018. Saat pelatihan keterampilan daur ulang limbah plastik peserta pelatihan yang terdiri dari ibu-ibu rumah tangga di kelurahan 12 ulu lorong pedatukkan darat tampak antusias mengikuti pelatihan ini hal ini terlihat pada Gambar 2. Ibu-ibu berhadap sering terdapat pelatihan semacam ini sehingga dapat bermanfaat bagi ibu-ibu rumah tangga yang tidak memiliki kesibukan rutin selepas urusan rumah.

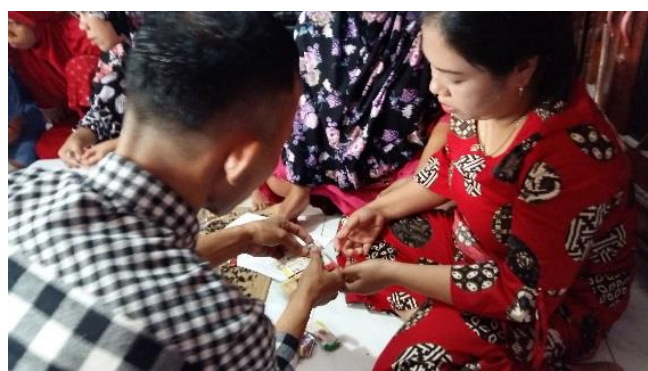

Gambar 2. Atusianme Ibu-ibu dalam mendaur ulang Limbah Plastik.

Dalam kegiatan ini diawal diberikan sedikit edukasi mengenai apa itu limbah, apa itu sampah dan apa bahaya sampah. Hal ini dilakukan dengan tujuan agar ibu-ibu tau bagaimana menyikapi sampah. Kebanyakan ibu-ibu tidak paham bahaya sambah bagi kesehatan dan lingkungan, sehingga dengan diberikan sedikit edukasi terkait sampah membuat ibu-ibu menjadi lebih antusias.

Pelaksanaan kegiatan pengabdian di kelurahan 12 Ulu Lorong Pedatukkan Darat, kota Palembang berjalan dengan baik. Program pengabdian berupa pelatihan pengelolaan sampah anorganik berupa plastik menjadi kreasi tas daur ulang perlu terus diupayakan mengingat produksi sampah rumah tangga semakin banyak dan didukung rendahnya kesadaran 3R, yaitu reuse (memakai kembali barang bekas yang masih bisa dipakai), reduce (berusaha mengurangi sampah), dan 
recycle (mendaur ulang sampah agar dapat dimanfaatkan). Hal ini menjadi pertimbangan untuk dicarikan cara yang tepat dalam mengelola sampah plastik, sehingga tidak mencemari lingkungan, tetapi justru mampu memberikan keuntungan bagi masyarakat. Salah satu caranya yaitu dengan menjadikan sampah plastik (bekas minuman instan) menjadi kreasi tas yang mempunyai nilai ekonomi.

Pada tahap awal program pengabdian, peserta pelatihan diberikan pengetahuan tentang sampah, jenis sampah, dan sumber sampah, pengelolaan sampah dan 3R (reduce, reuse, recycle), serta pengelolaan sampah anorganik menjadi aneka kreasi daur ulang. Dalam tahap ini peserta pelatihan diubah pola pikirnya terhadap sampah, "jika dulunya barang bekas langsung kita buang dan menjadi tumpukan sampah", maka pola pikir ini harus kita ubah menjadi "sampah dapat kita olah menjadi sesuatu benda yang berguna". Dengan menerapkan prinsip recycle, barang-barang bekas atau sampah dapat diolah kembali menjadi suatu bentuk yang memiliki daya guna seiring dengan kreatifitas yang dimiliki.

Seusai dari pemaparan apa itu limbah dan sebagainya berikutnya ibu-ibu diberikan kesempatan untuk memulai membuat tas dengan dibimbing. Dalam kesempatan ini yang dibuat ialah limbah dari susu Zee diolah menjadi tas sangkek untuk ke pasar. Tas keranjang yang dibuat dengan ukuran $30 \times 40 \mathrm{~cm}$. Pertama-tama plastik sachet susu Zee dipotong menjadi 3 bagian, selanjutnya dilakukan pelipatan ke dalam dengan tujuan agar potongan sachet menjadi lebih kuat dan tebal, selanjutnya menganyam potongan sachet Zee yang telah dilipat menjadi tas-tas keranjang belanja kepasar. Salah satu hasil kreasi warga dapat dilihat pada Gambar 3.

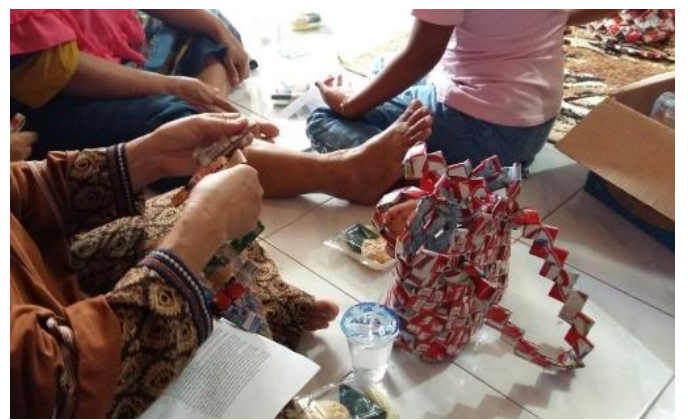

Gambar 3. Hasil Karya Salahsatu Warga.

Kegiatan pengabdian secara keseluruhan dapat dikatakan baik dan berhasil. Kegiatan pengabdian dapat meningkatkan pengetahuan ibu-ibu rumah tangga tentang pengelolaan sampah anorganik terutama plastik menjadi aneka kreasi tas daur ulang, serta memberdayakan mereka dalam pengelolaan sampah anorganik berupa plastik menjadi aneka kreasi tas daur ulang.

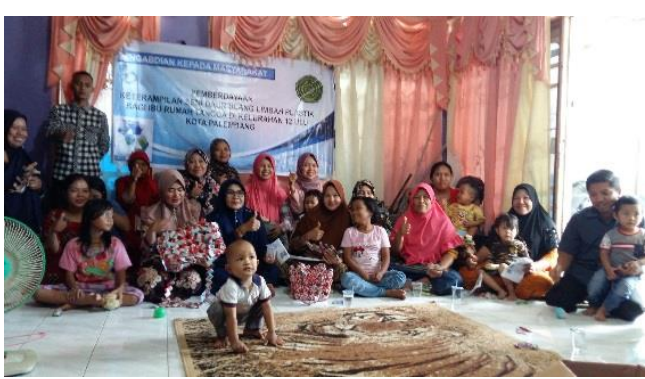

Gambar 4. Dokumentasi Seusai Kegiatan.

Ibu RT memberikan apresiasi dalam kegiatan ini. Ibuibu tampak antusias dalam mengikuti kegiatan ini. Bahkan ibu-ibu sangat semangat dalam belajar menganyam limbah plastik menjadi tas. Sehingga dapat diartikan bahwa kegiatan ini berjalan dengan baik.

Dapat dibayangkan apabila semua orang berlombalomba mengupulkan sampah plastik sachet terbayang begitu bersihnya lingkungan dari sampah plastik. Sehingga menurut salah satu warga yang berjualan es (Pop Ice dan Capucino Cincau) merasa senang karena mereka tidak bersusah payah lagi membuang sampah plastik bekas sachet minuman itu. Terlihat senyum bahagia ketika ibu Halimah bercerita.

\section{SIMPULAN}

Kegiatan pengabdian secara keseluruhan dapat disimpulkan bahwa target jumlah peserta pelatihan $(100 \%)$, ketercapaian tujuan pelatihan $(85 \%)$, dan kemampuan peserta dan penguasaan materi $(80 \%)$. Kegiatan pengabdian dapat meningkatkan pengetahuan ibu-ibu rumah tangga tentang pengelolaan sampah anorganik terutama plastik menjadi aneka kreasi tas daur ulang, serta memberdayakan mereka dalam pengelolaan sampah anorganik berupa plastik menjadi aneka kreasi tas daur ulang.

\section{UCAPAN TERIMA KASIH}

Ucapan terima kasih penulis tujukan kepada semua pihak yang membantu dalam menyukseskan kegiatan pengabdian masyarakat ini. Terima kasih penulis tujukan kepada Rektor Universitas Muhammadiyah Palembang Bpk Dr. Abid Djazuli, S.E.,M.M. Dekan FKIP Bpk Dr. H. Rusdy A. Siroj, M.Pd. dan ketua LPPM Bpk. Dr. Mustopa Marli Batubara, M.P. yang telah memberi dana dan fasilitas dalam kegiatan pengabdian masyarakat ini. Terima kasih juga peneliti sampaikan kepada Ibu RT dan ibu-ibu yang turut serta dalam kegiatan ini di kelurahan 12 Ulu Kota Palembang

\section{DAFTAR PUSTAKA}

Arief, M. Latar. (2012). Pengelolaan Limbah Industri. Jakarta: Etaprima.

Hadi, Anwar. (2015). Prinsip Pengelolaan Pengambilan Sampel Lingkungan. Jakarta: PT Gramedia Pustaka Utama.

Ginting, P. (2017). Sistem Pengelolaan Lingkungan dan Limbah Industri. Jakarta: Pustaka Sinar Harapan.

Ricky, M. (2015). Kesehatan Lingkungan. Jakarta: Esa Unggul. 
Kumar S., Panda, A.K., dan Singh, R.K., (2011). A Review on Tertiary Recycling of High-Density Polyethylene to Fuel, Resources, Conservation and Recycling Vol. 55 893-910.

Nusa, Idaman. (2010). Teknologi Pengolahan Air Limbah Rumah Sakit. Jakarta: BPPT.

Silviana, Safitri. (2010). Perencanaan Sistem Instalasi Pengolahan Air Limbah. Jakarta: UI Press.

Undang-undang RI Nomor 322009 tentang Kesehatan. 